\title{
Land Cover Classification Based on Multi-Date JERS-1 Imagery as a Basis for Deforestation Detection.
}

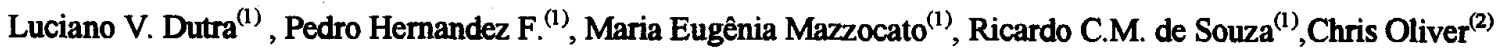 \\ (1) Instituto Nacional de Pesquisas Espaciais \\ 12.227-010 São José dos Campos, Brazil \\ Phone +55 12 345 6480/Fax: +55 12345 6468/E-mail: dutra@dpi.inpe.br
}

(2) Defense Evaluation and Research Agency (DERA)

Malvem, England U.K.

\begin{abstract}
Deforestation detection is a key issue on tropical environment monitoring. It has been done in Brazil based mainly on visual interpretation of optical images. Cloud coverage, however, is an impediment to have reliable estimates over several Amazonian areas. L band SAR data is a promising information source to monitor those areas. One possible approach, used in this work, is to analyse land use/cover change between successive dates to spot deforestation, being each consecutive land cover map obtained through JERS-1 land use/cover classification. Initially, each JERS-1 image is speckle filtered and a standard segmentation routine is then applied to each filtered channel. The result is an image in which each segment is represented by the average backscatter level within that segment. After segmentation stage, the segments are classified into four land use/cover classes of interest: pasture+bare soil, dirty pasture, secondary and primary forest, producing a land cover map for each year. Analysing the changes on the 1996 land cover maps related to the 1995 map, it was possible to point out areas of deforestation and other change classes. An assessment is done over an well known area near the Tapajós National Forest (Flona), in Para State, Brazil. The land use/cover maps and the change map are compared to reference areas defined by visual interpretation.
\end{abstract}

\section{INTRODUCTION}

Traditionally, deforestation in Brazil has been assessed using visual interpretation of a time series TM Landsat scenes[1]. The main drawbacks of such method are the cost and the unavailability of scenes over heavily cloudy areas. The use of radar satellite imagery, particularly L- band data, is a natural choice for replacement over cloudy area and as a complement to optical data analysis to improve deforestation detection accuracy.

A methodology is presented here for semi-automatic deforestation detection based on change detection of land use/cover maps produced by classification of JERS-1 images acquired in different dates. An ample area in Brazilian Amazônia, of size approximately equal to the area covered by a JERS-1 scene, was used to test the methodology, and covers most of the Tapajós National Forest and surroundings.
The Tapajós National Forest (FLONA) is located south of city of Santarem, Para State, Brazil, between the parallels $2: 40^{\prime}$ to $4: 10^{\prime}$ and the meridians $54: 45^{\prime}$ to $55: 00$. It borders on the east with Santarém-Cuiabá Highway and the west with Tapajos River. In the last few decades FLONA has presented dynamic alterations resulting from human occupation. Many of these areas have been abandoned and are under regeneration by secondary succession. FLONA is composed by several types of primary forest with different types of soil and soil relief. Among other classes, the following can be found in this region: 1) dense forest - dissected plateau (DFDP); 2) dense forest - high plateau (DFHP); 3) urban areas; 4) open forest (OF); 5) dense forest - sedimentary area (DFSA); 6) late secondary forest; 7) pasture; 8) bare soil; 9) abandoned (dirty) pasture; 10) water; 11) aquatic vegetation. Not all of them, however, are of interest for this study, and a subset was chosen as a basis for land use/cover classification, as described in the next section. It was used two JERS-1 scenes 405/306 (acquired October 10, 1995 and Aug 13, 1996) provided by NASDA under the Global Rain Forest Monitoring Project (GRFM). An yearly field trip was done in the area since 1993, for field classes recognisance and localisation[2]. TM scenes of same area ( 227/62C, acquired August 7, 1995 and August 25, 1996) were also used for reference.

\section{LAND USE/COVER CLASSIFICATION}

The analysis was done in two steps: 1) land cover/use maps for end of 1995 and end of 1996 were produced based on JERS-1 images; 2) after registering both land cover maps and observing the occurring changes on land use/cover it was possible to map deforestation, conversion of secondary forest, regeneration or stability.

Towards step 1, both JERS-1 scenes were speckled reduced using an algorithm based on simulated annealing which takes in account the gamma statistics of radar retums [3]. A segmentation method, based on region growing technique [4], is still applied to those filtered images for achieving further speckle reduction and best delineation of radar image segments with constant backscatter. 
Four land use/cover classes, considered as having relationship with deforestation detection, were defined for 1995 and 1996 scenes classification. The land use/cover classes used are: 1) forest - representing mainly the forests with flat relief (classes 2, 4, 5 and 6 mentioned in previous section); 2) secondary forest - areas with 2-5 years of regrowth; 3) dirty pasture - pasture which has been abandoned for at least one year; 4) pasture - areas with no, or almost no, low trees - or bare soil. Class forest can not represent properly, for the purposes of this work, forests with undulated relief like DFDP (class 1) and at certain extent DFSA (class 5), because of the excessive influence of the relief on radar returns.

The L-band radar signature for the mentioned classes were extracted by drawing training areas for all classes, in both dates, in several parts of the scene e obtaining respective histograms. The training sets for 95 and 96 images are not the same. The histograms represent the distribution of segment backscatter levels for each class. It was observed that there was a large intersection of backscatter ranges of the histograms spanned by secondary forest and forest classes. For defining which level would be used for separating secondary from primary forest, several simulations were done in order to reduced the impact of misclassification over the entire scene. As a result of this phase the following backscatter ranges (db) were used for each class ( Table 1).

Table 1: backscatter ranges for land use/cover classes definition (db)

\begin{tabular}{|c|c|c|c|c|}
\hline classes/ dates & \multicolumn{2}{|c|}{1995} & \multicolumn{2}{c|}{1996} \\
\hline $\begin{array}{c}\text { pasture or bare } \\
\text { soil }\end{array}$ & \multicolumn{2}{|c|}{$<-12.1$} & \multicolumn{2}{c|}{$<-11.2$} \\
\hline dirty pasture & -12.1 & -9.4 & -11.2 & -9.0 \\
\hline $\begin{array}{c}\text { secondary } \\
\text { forest }\end{array}$ & -9.4 & -8.3 & -9.0 & -7.9 \\
\hline forest & \multicolumn{2}{|c|}{$>-8.3$} & \multicolumn{2}{|c|}{$>-7.9$} \\
\hline
\end{tabular}

Some variation on backscatter ranges was noticed between different dates, probably due different humidity conditions. Considering the backscatter ranges for each year two land use/cover maps were produced. Tables 2 and 3 present the error matrices obtained using training sets for 95 and 96 land use/cover. The large intersection of the secondary forest and primary forest histograms causes fairly large confusion between secondary and primary forest on the error matrices. The behaviour was confirmed by manual inspection of the imagery, where forest signature in some places are very similar to the secondary forest.
Table 2: Error Matrix for 95 land cover map (\%)

\begin{tabular}{|l|c|c|c|c|}
\hline Class & $\begin{array}{l}\text { Secondary } \\
\text { forest }\end{array}$ & Forest & $\begin{array}{l}\text { Dirty } \\
\text { pasture }\end{array}$ & $\begin{array}{l}\text { Pasture } \\
\text { or bare } \\
\text { soil }\end{array}$ \\
\hline $\begin{array}{l}\text { Unclassi- } \\
\text { fied }\end{array}$ & 0 & 0 & 0 & 0 \\
\hline $\begin{array}{l}\text { Secondary } \\
\text { forest }\end{array}$ & 67,9 & 23,0 & 0,1 & 0 \\
\hline Forest & 15,4 & 77,0 & 0,2 & 0 \\
\hline $\begin{array}{l}\text { Dirty } \\
\text { pasture }\end{array}$ & 16,7 & 0 & 90,3 & 0 \\
\hline $\begin{array}{l}\text { Pasture or } \\
\text { bare soil }\end{array}$ & 0 & 0 & 9,4 & 100 \\
\hline \multicolumn{1}{|l|}{ Accuracy $=85,2 \%$} & Year $=1995$ \\
\hline
\end{tabular}

Table 3: Error Matrix for 96 land cover map (\%)

\begin{tabular}{|c|c|c|c|c|}
\hline Class & $\begin{array}{l}\text { Secondary } \\
\text { forest }\end{array}$ & Forest & $\begin{array}{l}\text { Dirty } \\
\text { pasture }\end{array}$ & $\begin{array}{l}\text { Pasture } \\
\text { or bare } \\
\text { soil }\end{array}$ \\
\hline $\begin{array}{l}\text { Unclassi- } \\
\text { fied }\end{array}$ & 0 & 0 & 0 & 0 \\
\hline $\begin{array}{l}\text { Secondary } \\
\text { forest }\end{array}$ & 47,8 & 3,5 & 1,0 & 0 \\
\hline Forest & 52,2 & 96,5 & 0,1 & 0,7 \\
\hline $\begin{array}{l}\text { Dirty } \\
\text { pasture }\end{array}$ & 0 & 0 & 83,4 & 4,1 \\
\hline $\begin{array}{l}\text { Pasture or } \\
\text { bare soil }\end{array}$ & 0 & 0 & 15,5 & 95,2 \\
\hline \multicolumn{2}{|c|}{ Accuracy $=87,1 \%$} & Year $=1$ & & \\
\hline
\end{tabular}

\section{CHANGE DETECTION}

Change detection is achieved by determining changes in land use/cover maps of different dates. This approach has the quality of being suitable for multitemporal analysis in a year incremental basis. We take in account here the following land use dynamics classes: 1) deforestation, which is an activity observed when a forested area tums into pasture, bare soil or dirty pasture; 2) conversion, which is the activity of removing secondary forest or low trees from dirty pasture to implant pasture or agricultural field, and 3) regeneration, which is considered here the transformation of bare soil or pasture into dirty pasture or secondary forest.

Considering the above definitions, a land use/cover class change map is produced for the $95-96$ period. Fig. 1 shows a sample of 95 and 96 images, with respective segmentations and the change map. By visual analysis of the colour composition of 95 image (red) and 96 image (green and 
blue), with help of TM colour composition of both years and field data, a selection of reference sites, for those change classes, were defined over the change map. Table 4 shows the error matrix for this result.

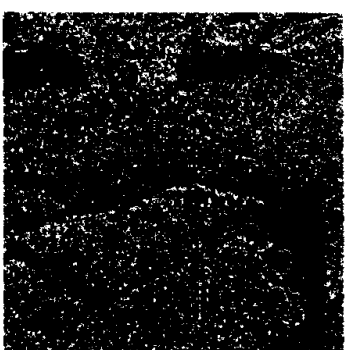

(a)

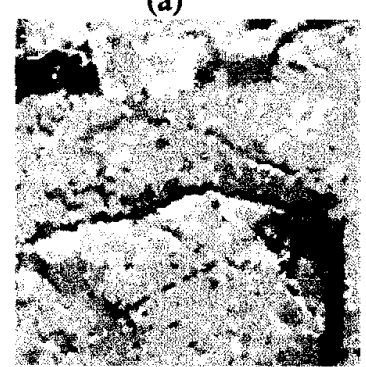

(c)

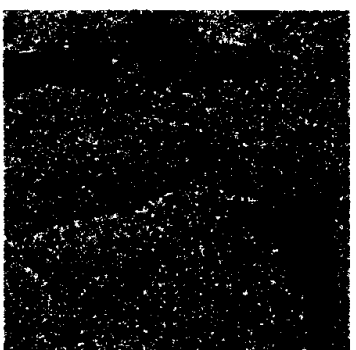

(b)

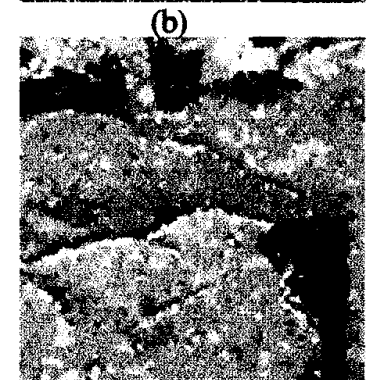

(d)

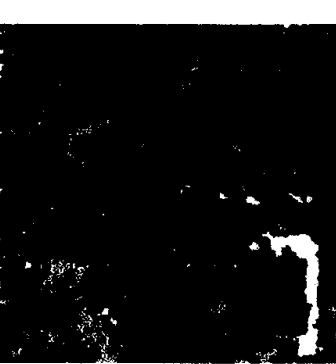

(e)

Fig. 1 Samples of 95 (a) and 96 (b) JERS-1 original images, with respective segmentations (c-d). (e) shows the change map with deforestation (red), conversion (maroon) and regeneration (green).

Table 4: Error Matrix for Change Map (\%)

\begin{tabular}{|c|c|c|c|}
\hline Class & $\begin{array}{l}\text { Deforesta- } \\
\text { tion }\end{array}$ & Conversion & Regeneration \\
\hline unclassified & 26,8 & 21,9 & 47,9 \\
\hline Deforestation & 57,5 & 32,7 & 0,1 \\
\hline Conversion & 15,3 & 44,8 & 1,1 \\
\hline Regeneration & 0,3 & 0,6 & 50,8 \\
\hline \multicolumn{2}{|r|}{ Accuracy $=50,6 \%$} & \\
\hline
\end{tabular}

\section{DISCUSSION}

Although the accuracy of land use/cover maps are reasonable, the accuracy of change map is not yet satisfactory. The definition of the separation threshold between secondary and primary forest is critical. In spite of the heavy speckle reduction achieved by segmentation, forest (secondary or primary) class radar signatures fluctuates, imposing difficulties on proper definition of classification boundaries. One conclusion that can be established is that precise characterisation of land use/cover classes is very important to decrease ambiguities in the classes signature definition. The use of other dates of JERS-1 images is expected to improve the overall change detection accuracy by using appropriate logical deduction on change sequence of the land use classes. Also, it is necessary to study the impact of non-uniformity on data calibration or rain over ample areas. New segmentation and change detection techniques, suitable for radar, will be also studied in a near future.

\section{ACKNOWLEDGEMENTS.}

The authors want to thank NASDA and RESTEC for supplying all high resolution data that made this research possible and Jet Propulsion Laboratory. The research was also partially funded by grants from Finep/PPG7 0808/95 and 0816/95 and CNPq 301 400/91-.1

\section{REFERENCES}

[1] INPE, IBAMA - Deforestation - Amazônia, São José dos Campos, 1998.

[2] P. Hemandez F., L.V. Dutra, G. Kuntschik, S.M. Soares, Processamento e Análise de dados JERS com Enfase em Floresta e Uso da Terra: Floresta Nacional do Tapajós. INPE, São José dos Campos, SP, Brazil, 1997 (INPE 6387-RPQ/678).

[3] NASoftware, Caesar: User's Guide. Version 2.1. Liverpool, 1994.

[4] INPE, SPRING: Sistema de Processamento de Informações Georeferencidas. Versão 2.0 - Ed. Netgis, São José dos Campos, 1997. 4v. 